07.2

\title{
Исследование ионной имплантации азота через слой нитрида кремния для межприборной изоляции силовых GaN/Si-транзисторов
}

\author{
() В.И. Егоркин ${ }^{1}$, С.В. Оболенский ${ }^{2}$, В.Е. Земляков ${ }^{1}$, А.А. Зайцев ${ }^{1, \uparrow, ~ В . И . ~ Г а р м а ш ~}{ }^{1}$ \\ ${ }^{1}$ Национальный исследовательский университет „МИЭТ“, Зеленоград, Москва, Россия \\ ${ }^{2}$ Нижегородский государственный университет им. Н.И. Лобачевского, Нижний Новгород, Россия \\ ฯE-mail: Ziko27@yandex.ru
}

Поступило в Редакцию 5 апреля 2021 г. В окончательной редакции 27 мая 2021 r. Принято к публикации 4 июня 2021 г.

\begin{abstract}
Представлены результаты исследования и разработки метода ионной имплантации азота через пассивирующий слой плазмохимического нитрида кремния для гетероструктуры $\mathrm{AlGaN} / \mathrm{GaN}$ на подложке кремния в сравнении с традиционным плазмохимическим травлением. Использование такого слоя упрощает изготовление транзисторов и получение изоляции благодаря возможности смещения максимума распределения имплантированных ионов к поверхности полупроводника. За счет использования легированных углеродом буферных слоев и ионной имплантации азота получено увеличение пробивного напряжения транзисторов до $650 \mathrm{~V}$.
\end{abstract}

Ключевые слова: ионная имплантация, пробивное напряжение, нитрид галлия, силовой транзистор.

DOI: 10.21883/PJTF.2021.18.51465.18805

Транзисторы с высокой подвижностью электронов на основе гетероструктур $\mathrm{AlGaN} / \mathrm{GaN}$ интенсивно исследуются с целью разработки полупроводниковой элементной базы следующего поколения для СВЧ-электроники и скоростной силовой электроники. Особенно многообещающе здесь выглядит нитрид-галлиевая гетероструктура на кремниевой подложке из-за более низкой стоимости и большого размера пластины. За последние несколько лет благодаря внедрению легированных буферных слоев [1], затворов p-типа проводимости [2], полевых электродов [3] параметры транзисторов $\mathrm{GaN}$ на $\mathrm{Si}$ были значительно улучшены. Еще одним этапом технологического процесса изготовления транзисторов, над которым постоянно ведется работа с целью уменьшения утечек и повышения пробивных и рабочих напряжений, является формирование межприборной изоляции. Для изоляции активных областей транзисторов обычно используют плазменное травление на основе $\mathrm{Cl}_{2}$. Как показано в [4], травление может привести к контакту между металлом затвора и слоем двумерного электронного газа на боковой стенке мезы, что ведет к значительному току утечки затвора. Использование изоляции с помощью ионной имплантации вместо травления помогает избежать этой проблемы. Кроме того, метод изоляции на основе ионной имплантации обеспечивает планарность конструкции. При определенной концентрации имплантируемых ионов образуются стабильные глубокие ловушки для электронов и дырок, превращающие полупроводник в материал с высоким удельным сопротивлением. Для изоляции ионной имплантацией использовались различные типы ионов (H, He, N, Fe, C, Al, О и F) [5,6]. Из них мы выбрали азот, так как этот газ безопасен и более технологичен для получения потока ионов.
Целью настоящей работы является исследование процесса имплантации ионов азота через слой пассивирующего нитрида кремния для формирования межприборной изоляции. Это упрощает формирование затворной металлизации, так как этот же диэлектрик используется для изготовления $T$-образного затвора. Кроме того, упрощается ионная имплантация, так как вместо легирования с несколькими дозами и энергиями возможно использование одного легирования за счет смещения максимума распределения имплантированных ионов к поверхности полупроводника.

Моделирование распределения ионов в структурах проводилось с использованием известного алгоритма TRIM (SRIM). Необходимо было оценить дозу облучения азотом, приводящую к подавлению проводимости в слое двумерного электронного газа, формирующегося на границе $\mathrm{AlGaN} / \mathrm{GaN}$ и имеющего концентрацию электронов более $10^{20} \mathrm{~cm}^{-3}$ (прямой пересчет из поверхностной концентрации, известной из экспериментальных данных).

Из расчетов следует, что использование нитрида кремния изменяет распределение ионов, особенно при энергиях от 50 до $100 \mathrm{keV}$. При уменьшении энергии имплантируемых ионов максимум распределения ионов смещается к поверхности полупроводника в область гетерограницы $\mathrm{AlGaN} / \mathrm{GaN}$, что позволяет гораздо эффективнее подавлять проводимость электронного газа. В стандартной технологии, где имплантация производится без применения слоя нитрида кремния, максимум распределения радиационных дефектов расположен гораздо глубже, чем гетерограница $\mathrm{AlGaN} / \mathrm{GaN}$, что затрудняет подавление проводимости. 


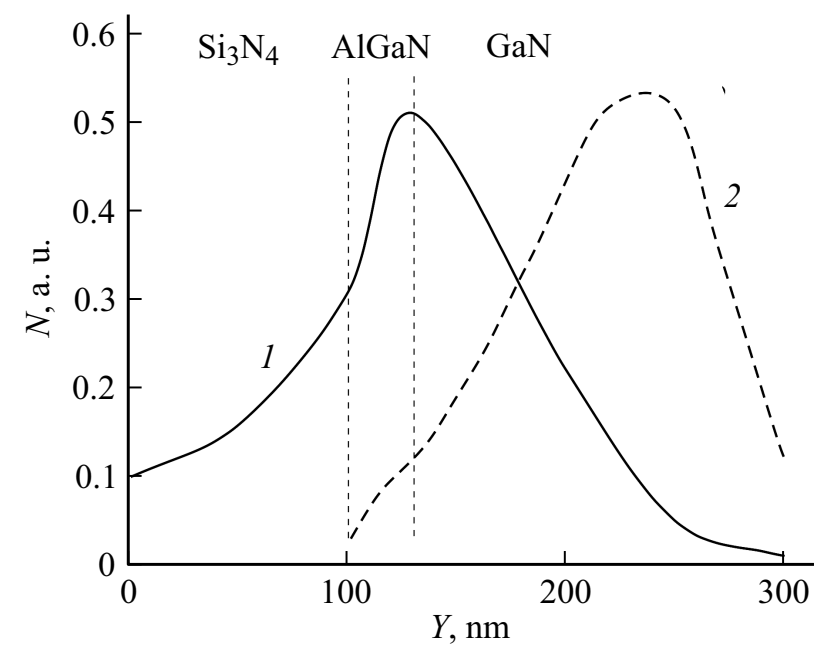

Рис. 1. Профили распределения ионов азота, имплантированных с энергией $85 \mathrm{keV}$, в гетероструктуре $\mathrm{AlGaN} / \mathrm{GaN}$ со слоем нитрида кремния $100 \mathrm{~nm}$ на поверхности (1) и без него (2).

Помимо указанного расчеты показали сильную зависимость распределения ионов от плотности плазмохимического нитрида кремния. Известно, что в зависимости от условий осаждения плотность плазмохимического нитрида кремния может меняться от 2.0 до $2.8 \mathrm{~g} / \mathrm{cm}^{3}$ [7]. Для используемого нами $\mathrm{Si}_{3} \mathrm{~N}_{4}$ были проведены специальные измерения на микрогравитометре HR100AZ. Получено значение плотности $2.7 \mathrm{~g} / \mathrm{cm}^{3}$.

Для этого значения плотности диэлектрика были рассчитаны распределения ионов для энергий 50, 70, 75, 80, 85, 90 и $100 \mathrm{keV}$. Кроме того, были проведены расчеты распределения ионов при значениях плотности нитрида кремния 2.15 и $3.17 \mathrm{~g} / \mathrm{cm}^{3}$, соответствующих аморфному и кристаллическому состоянию [8]. Также моделировалось распределение дефектов в структуре при наличии слоя нитрида кремния и без него.

В результате расчетов получено, что при изменении энергии имплантируемых ионов азота максимум распределения дефектов может смещаться по глубине от 60 до $300 \mathrm{~nm}$, так что концентрация дефектов на границе раздела $\mathrm{AlGaN} / \mathrm{GaN}$ варьируется более чем на порядок величины при одинаковой дозе имплантируемых ионов. Для значения плотности нитрида кремния $2.7 \mathrm{~g} / \mathrm{cm}^{3}$ и толщины $100 \mathrm{~nm}$ получено, что максимум распределения имплантированных ионов азота располагается на границе $\mathrm{AlGaN} / \mathrm{GaN}$ при энергиях ионов $75-85 \mathrm{keV}$ (рис. 1). При этом концентрация дефектов на указанной границе раздела достигала значений более $10^{20} \mathrm{~cm}^{-3}$ при уровнях облучения более $200-500 \mu \mathrm{C} / \mathrm{cm}^{2}$. Это позволяло нейтрализовать имеющееся на границе $\mathrm{AlGaN} / \mathrm{GaN}$ сопоставимое по величине количество электронов.

Эксперименты по получению межприборной изоляции проводились на установке ионного легирования IBS IMC200. Были взяты образцы гетероструктур $\mathrm{AlGaN} / \mathrm{AlN} / \mathrm{GaN}$ на кремнии с легированным и нелеги- рованным переходным слоем (буфером) от подложки [9]. Толщина слоя $\mathrm{AlGaN} 25 \mathrm{~nm}$, концентрация Al 25\%. Для тестирования межприборной изоляции изготовлена тестовая структура (рис. 2) из омических контактов истока и стока с расстоянием между ними $5 \mu \mathrm{m}$ и контактными площадками для измерительного зонда.

С применением двухслойной литографии формировался рисунок тестовой структуры, затем осаждалась многослойная металлизация омических контактов на основе $\mathrm{Ti} / \mathrm{Al} / \mathrm{Ni} / \mathrm{Au}$, и методом взрыва в органических растворителях была получена топология тестовой структуры. Далее омические контакты вжигались при температуре $870^{\circ} \mathrm{C}$ и осаждался плазмохимический нитрид кремния [10]. Достаточно толстый фоторезист $(3 \mu \mathrm{m})$ использовался в качестве маски для ионной имплантации. Имплантация изолировала область между тестовыми омическими контактами. Вместе с тестами формировались транзисторные структуры с длиной затвора $0.7 \mu \mathrm{m}$, шириной $100 \mu \mathrm{m}$. На транзисторах контролировались удельный ток и пробивное напряжение транзистора в режиме отсечки (напряжение на стоке транзистора при напряжении на затворе транзистора, при котором ток стока минимален).

Ионная имплантация азота проводилась с набором дозы от 100 до $1000 \mu \mathrm{C}$ на двух образцах (с нелегированным и легированным буфером) и измерениями через каждые $100 \mu \mathrm{C}$. Токи утечки по тестовой структуре наблюдались до уровня в $500 \mu \mathrm{C}$, и начиная с $600 \mu \mathrm{C}$ токи уменьшились до уровня менее $1 \mathrm{nA}$. Пробивное напряжение через структуру также стабилизировалось. Для сравнения тестовая структура была изготовлена также при травлении в низкоэнергетической плазме $\mathrm{BCl}_{3}$ на глубину 100 и $200 \mathrm{~nm}$. Сразу после травления измерения показывали отсутствие утечек по полю, однако после осаждения плазмохимического нитрида кремния утечки резко возрастали.

На рис. 3, $а$ представлены измеренные токи утечки в тестовой структуре: токи утечки после травления гетероструктуры и нанесения нитрида кремния (кривая 1), токи утечки для нелегированного буфера (кривая 2), токи утечки для буфера, легированного углеродом (кривая 3). При использовании легированного буфера и

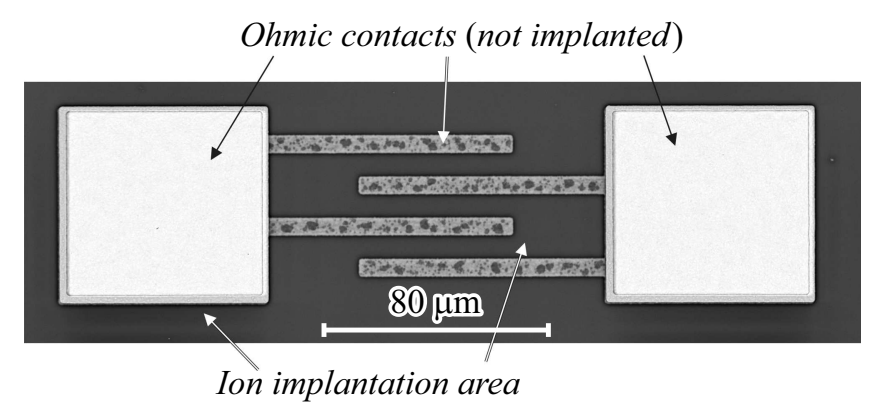

Рис. 2. Изображение тестовой структуры на межприборную изоляцию, полученное методом растровой электронной микроскопии. Расстояние между омическими контактами $\sim 5 \mu \mathrm{m}$. 

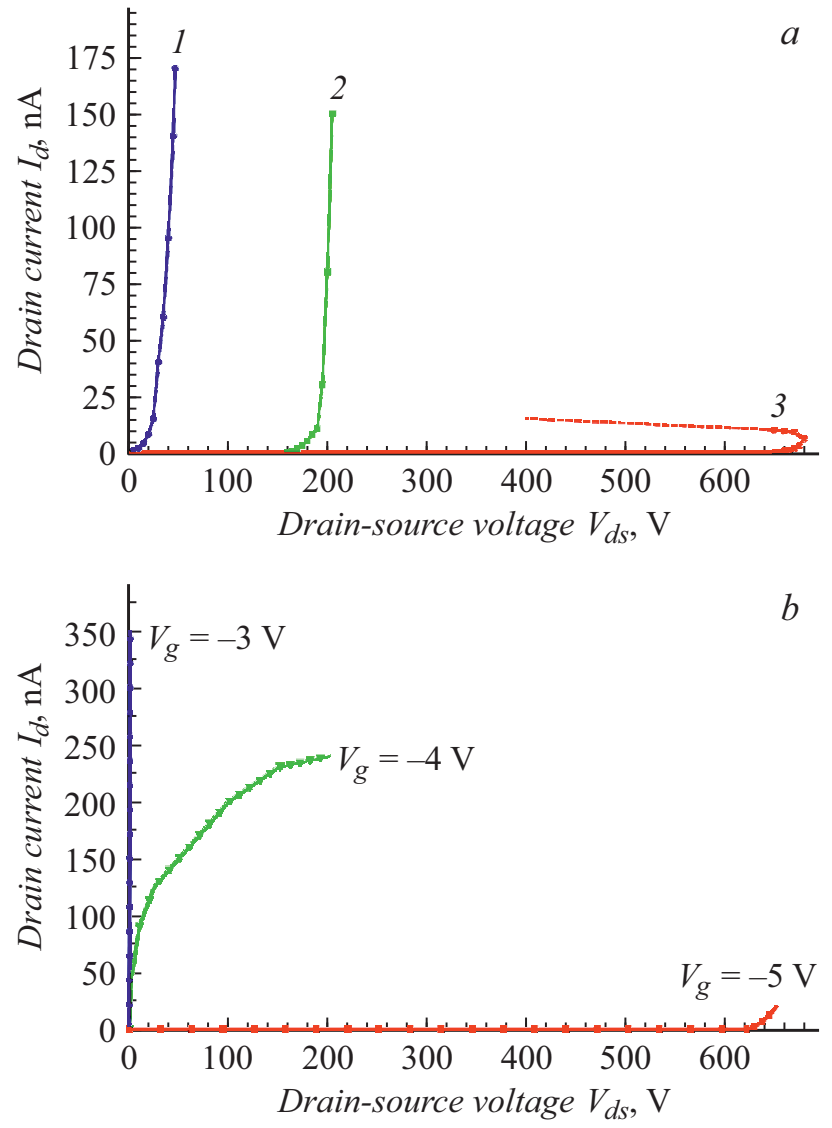

Pис. 3. $a-$ зависимости тока утечки в тестовой структуре от напряжения между омическими контактами. 1 - после травления в плазме $\mathrm{BCl}_{3}, 2$ - после ионной имплантации с нелегированным буфером гетероструктуры, 3 - после ионной имплантации с легированным буфером гетероструктуры. $b-$ вольт-амперная характеристика тестового полевого транзистора в режиме отсечки.

межприборной изоляции на основе имплантации азота наблюдается почти полное отсутствие токовых утечек и возрастание пробивного напряжения практически до уровня пробоя воздушного зазора между контактами.

Измерения тестовых транзисторов показали, что имплантация ионами азота в комбинации с буфером гетероструктуры, легированным углеродом, позволяет получать полевые транзисторы с пробивным напряжением в режиме отсечки до $600 \mathrm{~V}$ (рис. $3, b$ ) и удельными токами утечки менее $1 \mathrm{nA}$ на миллиметр ширины затвора.

\section{Финансирование работы}

Полученные результаты исследований достигнуты в ходе реализации проекта НИУ МИЭТ с использованием мер государственной поддержки развития кооперации российских образовательных организаций высшего образования, государственных научных учреждений и организаций, реализующих комплексные проекты по созданию высокотехнологичного производства, преду- смотренных постановлением Правительства РФ № 218 от 9 апреля 2010 г. (проект НИУ МИЭТ „Разработка технологии и технологическая подготовка к производству кристаллов транзисторов на основе гетероструктур нитрида галлия на подложке кремния диаметром $150 \mathrm{~mm}$ для силовых преобразовательных модулей“, соглашение № 075-11-2019-068 от 26 ноября 2019 г.).

\section{Конфликт интересов}

Авторы заявляют, что у них нет конфликта интересов.

\section{Список литературы}

[1] I.B. Rowena, S.L. Selvaraj, T. Egawa, IEEE Electron Dev. Lett., 32 (11), 1534 (2011). DOI: 10.1109/LED.2011.2166052

[2] В.И. Егоркин, В.А. Беспалов, А.А. Зайцев, В.Е. Земляков, В.В. Капаев, О.Б. Кухтяева, Изв. вузов. Электроника, 25 (5), 391 (2020). DOI: 10.24151/1561-5405-2020-25-5-391-401

[3] W.M. Waller, M. Gajda, S. Pandey, J.J.T.M. Donkers, D. Calton, J. Croon, S. Karboyan, J. Šonský, M.J. Uren, M. Kubal, IEEE Trans Electron Dev., 64 (3), 1197 (2017). DOI: 10.1109/TED.2017.2654800

[4] S.R. Bahl, J.A. Delalamo, IEEE Electron Dev. Lett., 13 (2), 195 (1992). DOI: 10.1109/55.144979

[5] H. Kasai, H. Ogawa, T. Nishimura, T. Nakamura, Phys. Status Solidi C, 11 (3-4), 914 (2014). DOI: 10.1002/pssc.201300436

[6] A. Taube, E. Kaminska, M. Kozubal, J. Kaczmarski, W. Wojtasiak, J. Jasinski, M.A. Borysiewicz, M. Ekielski, M. Juchniewicz, J. Grochowski, M. Myśliwiec, E. Dynowska, A. Barcz, P. Prystawko, M. Zajac, R. Kucharski, A. Piotrowska, Phys. Status Solidi A, 212 (5), 1162 (2015). DOI: $10.1002 /$ pssa.201431724

[7] H. Huang, K.J. Winchester, A. Suvorova, B.R. Lawn, Y. Liu, X.Z. Hu, J.M. Dell, L. Faraone, Mater. Sci. Eng. A, 435-436, 453 (2006). DOI: 10.1016/j.msea.2006.07.015

[8] Е.А. Тарасова, Е.С. Оболенская, А.В. Хананова, С.В. Оболенский, В.Е. Земляков, В.И. Егоркин, А.В. Неженцев, А.В. Сахаров, А.Ф. Цацульников, В.В. Лундин, Е.Е. Заварин, Г.В. Медведев, ФТП, 50 (12), 1599 (2016). DOI: $10.21883 / \mathrm{ftp} .2016 .12 .43883 .29$

[9] D.S. Arteev, A.V. Sakharov, W.V. Lundin, E.E. Zavarin, D.A. Zakheim, A.F. Tsatsulnikov, M.I. Gindina, P.N. Brunkov, J. Phys.: Conf. Ser., 1697, 012206 (2020). DOI: $10.1088 / 1742-6596 / 1697 / 1 / 012206$

[10] В.И. Гармаш, В.Е. Земляков, В.И. Егоркин, А.В. Ковальчук, С.Ю. Шаповал, ФТП, 54 (8), 748 (2020). DOI: $10.21883 /$ FTP.2020.08.49646.9398 